\title{
ANTONIO GAMONEDA: POÉTICA DE LA POBREZA*
}

\section{Antonio REY HAZAS}

Universidad Autónoma de Madrid

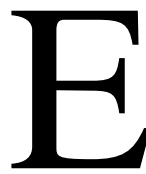

$\mathrm{n}$ el acercamiento, siempre difícil para quien busca claridades, a la personalísima y oscura poesía de Antonio Gamoneda, voz verdaderamente única en la lírica española, no ya actual, sino de todos los tiempos, he decidido, tras muchas idas y venidas, vueltas y revueltas, seguir el camino teórico de la pobreza, o mejor, de la poética de la pobreza, marcado por el propio poeta, como es sabido, en su Discurso del Premio Cervantes 2006.

El Libro del frío, por ejemplo, abre la puerta a mis reflexiones sobre la poética de la pobreza:

Hubo un tiempo en que mis únicas pasiones eran la pobreza y la lluvia.

Ahora siento la pureza de los límites y mi pasión no existiría si supiese su nombre. ${ }^{1}$

La pasión explícita de la pobreza real me permite comenzar la indagación teórica sobre la pobreza poética, a partir de las palabras leídas por Gamoneda en su Discurso del Premio Cervantes 2006, donde confiesa, puesto a preguntarse por el acontecer de su escritura, y a sabiendas de que las claves están en su vida y en su calidad existencial, que:

\begin{abstract}
pronto se me depara la evidencia de algo que, más que cualquier otra circunstancia o razón, ha condicionado a una y a otra, a mi vida y a mi escritura. Hablo de la pobreza. [...] Porque yo vengo de la penuria y del trabajo alienante. [...] Tengo que pensar que sí, que existe un estado pasional del pensamiento nacido en la pobreza y servido por el infortunio; un algo que, de aquí en adelante, nombraré diciendo simplemente cultura de la pobreza, y que esta cultura es, de algún modo, diferenciable de la que prospera a partir de una situación privilegiada. $^{2}$
\end{abstract}

Esa, entre otras, es la razón fundamental por la que Gamoneda se siente unido con Cervantes y con Juan de la Cruz:

Es verdad que, en 1936, en mi casa había un solo libro en el que aprendí a leer. [...] Un libro de poesía escrito por mi padre. Es verdad así mismo que mi primera información sobre la vida civil consistió en advertir la horrible represión en el barrio más tristemente obrero de León, y es verdad también que, al día siguiente de cumplir catorce años, a las cinco de la mañana, yo estaba cargando carbón en la caldera del extinguido

\footnotetext{
* Las páginas que siguen son apenas el esbozo de un proyecto mucho más ambicioso y extenso sobre la poética de la pobreza que, a mi entender, preside buena parte del quehacer lírico de Antonio Gamoneda, y para cuya realización cabal necesito más tiempo y, obvio es decirlo, la colaboración del poeta. En principio, por tanto, me limito a trazar algunas líneas maestras del trabajo, a la luz de Cervantes.

${ }^{1}$ A. Gamoneda (2004), Esta luz. Poesía reunida (1947-2004), 335.

${ }^{2}$ Véase http://www.uah.es/universidad/premio_cervantes/documentos/discurso_gamoneda.pdf.
} 
Banco Mercantil y que, a esa misma hora, mi madre, desde otra hora lejana del día anterior, inclinaba más de la cuenta su cabeza sobre una máquina Singer.

Pero, dentro de la cultura de la pobreza, ¿quién soy yo al lado de un François Villon, de un César Vallejo o de un Miguel de Cervantes?

Miguel de Cervantes, para permanecer en la vida, tenía que ofrecerse a la muerte, vender su sangre en el mercado de las grandes empresas negociadas a la contra entre los poderosos y extender su mano ante estos mismos mendigando auxilios; no pudo hacer lo que antes llamé «estudios avanzados», no sabía latín ni cursó en la universidad; y quizá hubo de mirarse a sí mismo con dolor o con desprecio en razón de alguna negra personería y del escondido comercio que de su cuerpo habían de hacer sus hermanas.

Yo quiero decir algo sobre la obra creativa de Cervantes considerando que fue hecha, precisamente, desde la pobreza. En modo general, se ha considerado la presencia de esta pobreza en su vida, pero quizá no se ha estimado como causa de peculiaridad en su obra.

Cervantes, pensando en su escritura estrófica, sabiendo o no sabiendo lo que decía, hablaba con pesadumbre de «la gracia que no quiso darme el cielo». Sin embargo fue él quien encendió la poesía -digo la poesía- en el interior del discurso narrativo y dio cuerpo a las revelaciones quizá más bellas, más increíbles y ciertas, surgidas de la lengua española. [...]

El conocimiento vacilante que tiene Cervantes de la que es, en mi convicción, radical esencialidad poética de su obra prosística mayor, se corresponde, poco menos que punto por punto, con el «no saber sabiendo» de San Juan de la Cruz, que estaba poseído por una inocencia análoga: creía que estaba hablando únicamente de la experiencia mística, pero también estaba definiendo, con una precisión hasta ahora insuperada, la experiencia poética.

He dado en San Juan de la Cruz: [...] también él pertenece a la cultura de la pobreza. Juan de Yepes era hijo de unos muy humildes tejedores y, socialmente, un villano. Torpe en los oficios, parece que fue hábil -le adiestraría la caridad- en el cuidado de los sifilíticos. Sufrió hambre, cárcel y torturas, y padeció el temor a la Inquisición. Sí estudió, brevemente, latín y filosofía, pero su saber más real surge de la lectura alucinada del Antiguo Testamento, en particular del Libro de Job y del Cantar de los cantares, así como del conocimiento, incompleto e igualmente alucinado, de la mística sufí.

Vuelvo a Cervantes. Matizando el que he llamado «conocimiento vacilante» de la naturaleza de su propia obra, doy en otra hipótesis de Gaos, quien dice de Cervantes y del Quijote que «cuando empezó a escribirlo, no tenía idea cabal de lo que se proponía». Esta noción de la obra «inconsciente» es bienvenida por numerosos eruditos. Yo la comparto con serias reservas; no comparto las razones profundas de la motivación: yo entiendo que no es exactamente inconsciencia, sino que se trata de la inocencia presente en grandes poetas, y en otros no tan grandes, que es asimilable, insisto en ello, al «no saber» postulado por Juan de la Cruz.

Hay un juicio de Ortega y Gasset que mucho me importa, aunque sea por motivos que Ortega no vio o no quiso ver. Cito abreviadamente: «No existe libro alguno cuyo poder de alusiones simbólicas al sentido universal de la vida sea tan grande, $\mathrm{y}$, sin embargo, no existe libro alguno en el que hallemos menos [...] indicios $[\ldots]$ para su interpretación». Habla de un texto hermético. Preferiría que pensase en un texto inmensamente abierto. En cualquier caso, sabiéndolo o sin saber que lo sabe, Ortega alude al pensamiento poético ya en su modernidad.

La cita es larga pero jugosa: no sé a qué se refiere Gamoneda cuando se pregunta si Cervantes hubo de aceptar «alguna negra personería», ni voy a entrar en matizaciones de pequeño detalle, que no vienen al caso, como la de si Cervantes sabía latín o no, dado que seguramente lo leía, bien que mal, con alguna que otra dificultad, pero lo leía; o la de si su pobreza fue tan persistente, porque en ocasiones no lo fue, sino al contrario; aunque es verdad -y eso es lo que interesa- que comenzó a «engendrar» el Quijote, es decir, a pensar en su trazado y esbozar un plan de escritura, en plena pobreza, cuando acababa de arruinarse - lo que no era nada raro para él-y estaba preso en la cárcel de Sevilla; o, en fin, la de si se consideraba mal poeta, dado que no era así. Los culpables son los siguientes versos del Viaje del Parnaso (1614):

Yo, que siempre me afano y me desvelo por parecer que tengo de poeta 
la gracia que no quiso darme el cielo (I, vv. 25-27). ${ }^{3}$

Versos que, como ya dijo José Manuel Blecua hace muchos años ${ }^{4}$, son indudablemente irónicos y no presuponen en absoluto que Cervantes se considerara mal poeta, pues se juzgó otras veces poeta excelente, en el mismo Viaje del Parnaso (1614):

Yo el soneto compuse que así empieza, por honra principal de mis escritos,

Voto a Dios que me espanta esta grandeza. (IV, vv. 37-39)

A Cervantes le gustaba ironizar sobre sí mismo, y llamarse «poetón ya viejo», o poeta al menos «magnifico», ya que no magnífico: con acento llano, sin tilde; esto es, irónicamente. Pero todo eran bromas; burlas y veras. Porque huelga decir, y es lo cierto, que si un soneto era para él lo mejor de su obra -y no bromea-, en verdad se juzgaba a sí mismo como un excelentísimo poeta, pues cuando lo dice ya se habían publicado algunas de sus mejores obras en prosa, incluida la primera parte del Quijote (1605) y las Novelas ejemplares (1613), ambas con excelente acogida, además.

Pero insisto en que no quiero entrar en pequeños detalles para centrarme en la interesantísima hipótesis, a mi entender, de la cultura de la pobreza como determinante del quehacer poético de Cervantes y de Gamoneda, según se induce de las palabras del gran poeta asturleonés. Antes aclararé que Antonio Gamoneda usa siempre la expresión «cultura de la pobreza», de ámbito mucho más extenso que poética, como es bien sabido. Yo prefiero hablar de «poética de la pobreza», de ámbito obviamente más reducido, pero asimismo más centrado en el germen de la creación artística; aunque ambas palabras vengan a ser, finalmente, lo mismo.

Busquemos, en fin, las coincidencias entre ambos escritores, que son muy numerosas y muy significativas:

No deja de ser curioso, entrando ya en materia, que el éxito de Cervantes y Gamoneda llegara en los mismos días de sus vidas respectivas, cuando ambos alcanzaban la vejez. Son, en efecto, dos genios de reconocimiento tardío. Cervantes tenía 57 años cuando se publicó el Ingeniosos hidalgo a principios de 1605, y Gamoneda casi los mismos, uno menos, cuando alcanzó el Premio Nacional de Poesía por Edad, en 1987. Los dos habían pasado casi desapercibidos hasta ese momento. Son, en consecuencia, escritores de madurez, que triunfan ya viejos, y adquieren seguridad plena en su quehacer cuando ya tiene muchos años. Eso, ¡qué duda cabe!, condiciona, y mucho, su mirada. Seguramente la clave de esa mirada común de vejez se halla en un verso de Gamoneda, Arden las pérdidas: «Así es la vejez: claridad sin descanso» ${ }^{5}$.

Se ha dicho que la obra de Gamoneda tiene algo de libro único, de obra abierta y en marcha que es, a la vez, la misma y distinta, única y múltiple. Y así es, en efecto, como el propio poeta reconoce,

\footnotetext{
${ }^{3}$ Cito por mi ed. (1997), Cervantes. Obra Completa, 20.

${ }^{4}$ «La poesía lírica de Cervantes» (1948), Homenaje a Cervantes, Cuadernos de Ínsula,151-187. Firma con el pseudónimo de Joseph M. Claube.

${ }^{5}$ A. Gamoneda, Esta luz, op. cit., 461.
} 
dado que se reescribe constantemente. No en vano, cuando se publicó el libro clave para su devenir último, Edad, en 1988, Miguel Casado advirtió que el volumen no podía

ser considerado como una mera recopilación de sus libros de poemas escritos hasta ahora, $[\ldots]$ sino que había de serlo como un libro unitario, como un solo recorrido poético en el que se cruzan de manera singular cuarenta años de lenta escritura con un periodo reciente de reajuste, de reconstrucción, en que el poeta vuelve sobre sus textos. [...] Tal reescritura conlleva una experiencia apasionante de diálogo entre las diversas etapas de un mismo poeta $[\ldots]$ y, simultáneamente, esa comunidad misteriosa que subyace y nos permite leerlos todos como un solo texto. ${ }^{6}$

Curiosamente, Cervantes trabajaba la palabra de la misma manera, pues volvía siempre sobre sus obras y se reescribía a sí mismo constantemente, y no solo en Rinconete y Cortadillo o en El celoso extremeño, como he demostrado hace una decena años en un largo artículo ${ }^{7}$.

Los dos son lectores empedernidos -en el caso de Cervantes, hasta de los «papeles rotos de las calles», y nada me extrañaría que fuera casi igual en el de Gamoneda-, de una capacidad crítica poco común, que les permite ver y valorar lo que suele pasar desapercibido para la mayoría. Supongo que no hará falta insistir en este punto, desde el momento que las opiniones críticas de Cervantes sobre sus contemporáneos condicionaron e incluso construyeron, en buena medida, una parte no desdeñable de la historia literaria española del Siglo de Oro. Y qué decir de Gamoneda, cuyos juicios sobre algunos poetas consagrados, entiéndase Gil de Biezma y Carlos Barral, sin ir más lejos, son tan acertados como arriesgados, de puro sinceros ${ }^{8}$, e implican además un cambio radical en la valoración histórica y en el concepto mismo de la poesía española contemporánea. Lo que no le impide ser, a la vez, el autor de la poética de la pobreza que me interesa ahora, a partir de sus sagaces juicios sobre Cervantes, Juan de la Cruz, Garcilaso, Góngora y otros. No se olvide que los dos poetas mencionados de la denominada Escuela de Barcelona eran ricos, y que eso implica -en este contexto- una mirada poética radicalmente distinta, porque, entre otras cosa, como dice Gamoneda: «existe un estado pasional del pensamiento nacido en la pobreza y servido por el infortunio; un algo que, de aquí en adelante, nombraré diciendo simplemente cultura de la pobreza, y que esta cultura es, de algún modo, diferenciable de la que prospera a partir de una situación privilegiada».

Hace catorce o quince años que Juan Carlos Rodríguez escribió un libro titulado La literatura del pobre, libro muy interesante que se planteaba analizar precisamente los rasgos diferenciadores y

\footnotetext{
${ }^{6}$ M. Casado (1988), «Introducción», Edad, 9.

${ }^{7}$ A. Rey Hazas (1999), «Cervantes se reescribe: teatro y Novelas Ejemplares», Criticón, 119-164.

8 «Hay una magnificación de algunos un tanto extraña - dice Gamoneda-. Carlos Barral, por ejemplo, no era un poeta... Barral estaba en el mundo editorial, era un hombre inteligente, pero quería ser precisamente lo que no podía; y no digamos Gil de Biedma: Gil de Biedma era inteligentísimo, hizo ensayos espléndidos sobre Eliot, y, sin embargo, dudo mucho que tenga un gran tamaño como poeta. Esta extraña confusión: la «Escuela de Barcelona» nucleando la «Generación del 50». Un amigo mío dice: «Eso es un invento, la Escuela de Barcelona es marketing». Yo tengo una experiencia que te voy a contar. Hace poco me invitaron a dar una lectura en el Palacio Real. Pagaban bien. Fui. Estaba con Ángel González, Claudio Rodríguez y con otros tres poetas jóvenes. De repente aquello se convirtió en un homenaje a Gil de Biedma y a Carlos Barral. Aparece la viuda de Carlos Barral y un señor con una guitarra cantando letras de Gil de Biedma. Y al día siguiente la prensa dice: «La Generación del 50 (en la que me incluyen, ya he dicho que erróneamente), rinde homenaje a los desaparecidos Carlos Barral y Jaime Gil de Biedma». Una manipulación. A mí no me llamaron para eso». Entrevista a Gamoneda de José Manuel López de Abiada, 30 / VIII, 1990, en AnMal electrónica (Analecta Malacitana), 15 de junio de 2004.
} 
peculiares de la mirada literaria, siempre distinta, del pobre. Esto es, algo semejante a lo que plantea ahora, bien que de otra manera, Antonio Gamoneda. Es obvio, a lo que creo, que nuestro poeta no ha leído el libro del profesor granadino, pero no deja de ser interesante la coincidencia, dado que Juan Carlos incluía el Quijote en la literatura del pobre, junto a la novela picaresca y otras obras narrativas. Al catedrático de la Universidad de Granada le interesaba, sobre todo, la mirada literaria del pobre. Al poeta asturleonés le interesa, como sabemos, la cultura de la pobreza. Y a mí, la poética de la pobreza. Pero no se preocupen, porque todo, bien entendido, viene a ser más o menos lo mismo: buscar en la pobreza la génesis de una escritura poética determinada, de una peculiar mirada literaria, distinta siempre a la que nace de situaciones socioeconómicas diferentes.

En mi opinión, uno de los puntos clave de esta poética es la libertad ${ }^{9}$. De hecho muchas novelas picarescas hacen un elogio indudable de la libertad del pícaro:

\begin{abstract}
Si he de decir lo que siento, la vida picaresca es vida -dice Lázaro de Tormes-, que las otras no merecen este nombre. Si los ricos la gustasen, dejarían por ella sus haciendas, como hacían los antiguos filósofos, que, por alcanzarla, dejaron lo que poseían. Digo por alcanzarla, porque la vida filosofal y picaral es una: sólo se diferencian en que los filósofos dejaban lo que poseían por su amor, y los picaros sin dejar nada, la hallan. Aquellos despreciaban sus haciendas para contemplar con menos impedimento en las cosas naturales, divinas y movimientos celestes; estos, para correr a rienda suelta por el campo de sus apetitos. Ellos las echaban en la mar, y estos en sus estómagos. Los unos, las menospreciaban, como cosas caducas y perecederas; los otros no las estiman por traer consigo cuidado y trabajo, cosa que desdice de su profesión, de manera que la vida picaresca es más descansada que la de los reyes, emperadores y papas. Por ella quise caminar, como por camino más libre, menos peligroso y nada triste. ${ }^{10}$
\end{abstract}

Juan de Luna, harto significativamente, une la mirada de pícaros y filósofos por su libertad, lo que no deja de ser muy interesante, pues no se debe olvidar que en los siglos XVI y XVII la mayor parte de los pensadores y humanistas, es decir, de los «filósofos», eran religiosos, lo que encaja a las mil maravillas con el filósofo, poeta y místico que fue San Juan, hermanado con Cervantes por la cultura de la pobreza, según Gamoneda. Y digo esto porque Juan Carlos Rodríguez a la inversa, deja fuera de la libertad a curas, frailes y monjas, es decir, deja fuera al carmelita descalzo Juan de la Cruz, igual que a Teresa la Santa, fray Luis de León, Tirso de Molina, o los propios Lope de Vega y Calderón de la Barca, ordenados sacerdotes en su madurez. Las razones de Juan Carlos son obvias, aunque, a mi entender, necesitan una matización precisa, pues funcionan a menudo de forma muy diferente a como él piensa, incluso revesada, en los Siglos de Oro, dado que las fuertes ataduras de los religiosos les hacían incluso abandonar los hábitos en ocasiones, en busca de una libertad que les estaba vedada, y eso implica que la libertad formaba parte de sus anhelos más queridos con muchísima frecuencia y, en consecuencia, era un elemento básico de sus miradas. No en vano, Juan de Luna dice lo siguiente:

Qué rumiar llevé por todo el camino, de mis buenos gitanos, de su vida, costumbres y trato! Espantábame mucho cómo la justicia permitía públicamente ladrones tan al descubierto, sabiendo todo el mundo que su trato y contrato no es otro que el hurto. Son un asilo y añagaza de bellacos, iglesia de apóstatas y escuela de maldades; particularmente me admiré de que los frailes dejasen su vida descansada por seguir la desastrada y aperreada del gitanismo. Y no hubiera creído ser verdad lo que el gitano me dijo, si no me hubiera mostrado un cuarto de legua del rancho, detrás de las paredes de un arrañal, un gitano y una gitana:

\footnotetext{
${ }^{9}$ Véase mi libro Poética de la libertad y otras claves cervantinas, 2005.

${ }^{10}$ Cito por la ed. de P. Piñero, Juan de Luna (1977), Segunda parte del Lazarillo de Tormes, 1620, $193-194$.
} 
él rehecho y ella carillena. Él no estaba quemado del sol, ni ella curtida de las inclemencias del cielo. El uno cantaba un verso de los salmos de David y el otro respondía con otro. Advirtióme el buen viejo que aquellos eran fraile y monja, que no había más de ocho días habían venido a su congregación, con deseo de profesar más austera vida. ${ }^{11}$

No se olvide, además, que no se trata de meras ficciones, pues casos como este, relatado por Juan de Luna, más que invenciones literarias, eran elaboraciones, más o menos manipuladas o exageradas, de sucesos sacados de la realidad. Recordaré, simplemente, un caso real narrado por las Cartas de jesuitas, en concreto por una epístola fechada en Madrid, en enero de 1635. Dice así:

En Osuna ahorcaron días pasados a un carmelita descalzo, llamado don Francisco de Arana, el cual era natural de Santo Domingo de la Calzada e hijo de padres honrados. Cediendo a sus malas inclinaciones, se metió a ladrón de caminos y valentón. Cogiéronle y, como dejo dicho, le ajusticiaron delante de las mismas puertas de la catedral. ${ }^{12}$

No a todos los religiosos, por tanto, es aplicable la falta de libertad, ni a todos los nobles o burgueses, y menos en el Siglo de Oro, aunque pueda generalizarse pedagógicamente. En los siglos XVI y XVII, unos y otros, nobles y religiosos, estaban necesariamente encorsetados; los unos, por las exigencias de la honra; los otros, por las del dogma y la moral; pero todos sin libertad. Y no se sabía qué prohibiciones o vetos eran más importantes, si los de Dios, o los del rey, si los de la moral o los de la honra; porque todos eran omnipotentes, aunque los caballeros pusieran a veces su honra por delante de Dios, y los clérigos sus preceptos por delante del honor. Pero todo eran prohibiciones, vetos e impedimentos incluso para el centro del poder, para la corte y los cortesanos, es decir, para los más poderosos y ricos, sometidos a la rigurosa etiqueta borgoñona, que impedía incluso al mismo rey hacer lo que quisiera y le encorsetaba hasta extremos que hoy nos parecerían increíbles, como que el rey no podía reír ni sonreír en público, ni comer en privado, etc.

Por eso, en busca de la libertad, muchos deseaban entonces ser pobres y vagabundos, es decir, anhelaban ser pícaros. Por eso, muchos nobles, como relata Cervantes en La ilustre fregona (1613), viajaban a las almadrabas gaditanas de Zahara, «donde es el finibusterrae de la picaresca» para convertirse en pícaros y vivir como y con los pícaros más endurecidos y arriscados de la época, como hacen Carriazo y Avendaño. El hecho novelado por Cervantes era una realidad entonces, a juzgar por lo que dice el jesuita padre León en su interesantísimo Compendio de $1619^{13}$. Incluso la idea medular de la novela cervantina puede proceder de la realidad de las almadrabas de Zahara, pues dice Herrera Puga que

\footnotetext{
un tipo muy original de estos lugares fue el pícaro procedente de la nobleza. Nadie pudiera creerlo, pero, aunque resulte extraño, se dieron casos de hijos de nobles que, atraídos por aquel ambiente, llegaron dispuestos a adaptarse en todo a la vida y costumbres de la picaresca allí reinante. Expresamente lo dice León, después de haber tenido varios encuentros con «hijos de gente principal». [...] Con la misma facilidad que se les despedía, con mayor aún volvían a aparecer, atraídos sin duda por el sabor picaresco de la tierra. [...] Sin duda, estos casos tienen su interés particular, pero lo más notable es que fueron bastante frecuentes. En distintas ocasiones se presentó allí el hijo de un conde de España. Varias veces lo devolvieron a su padre, y otras tantas volvió a aparecer. Tanta insistencia no era fácil comprenderla, y así, después de cierto diálogo,
}

\footnotetext{
${ }^{11}$ J. de Luna, Segunda parte del Lazarillo de Tormes, op. cit., 217.

${ }^{12}$ Cartas de algunos padres de la Compañía de Jesús, tomo I, Memorial Histórico Español (1861), 124-125.

${ }^{13}$ Apud., P. Herrera Puga (1974), Sociedad y delincuencia en el Siglo de Oro, 340 y 341.
} 
manifestó que su única pretensión era «ser pícaro», como otros muchos que vivían en aquella región. Sin duda que estos ejemplos fueron los que le dieron al padre León el fundamento para bautizar a esta región como «refugio de pícaros», y a Cervantes, con el título de «cátedra de la picaresca». ${ }^{14}$

El pícaro y el vagabundo, el pobre, en suma, tenía más libertad que el rico, que noble y el burgués, por la sencilla razón de que ignoraba las prohibiciones de la honra, la moral, la corte, el deber, el dogma, etc. Recordemos ahora unas ilustrativas palabras de Mateo Alemán sobre el particular, en la primera parte del Guzmán de Alfarache (1599):

¡Oh tú, dichoso dos, tres y cuatro veces, que a la mañana te levantas a las horas que quieres, descuidado de servir ni ser servido! Que, aunque es trabajo tener amo, es mayor tener mozo. [...] Al mediodía la comida segura, sin pagar cocinero ni despensero; [...] sin cuidado de la gala, sin temor de la mancha ni codicia del recamado; libre de guardar, sin recelo de perder; no invidioso, no sospechoso, sin ocasión de mentir y maquinar para privar. Eso te importa ir solo que acompañado, apriesa que de espacio, riendo que llorando, corriendo que trepando, sin ser notado de alguno. Tuya es la mejor taberna donde gozas del mejor vino, el bodegón donde comes el mejor bocado; tienes en la plaza el mejor asiento, en las fiestas el mejor lugar; en el invierno al sol, en el verano a la sombra; pones mesa, haces cama por la medida de tu gusto, como te lo pide, sin que pagues dinero por el sitio ni alguno te lo vede, inquiete ni contradiga; remoto de pleitos, ajeno de demandas, libre de falsos testigos; [...] descuidado que te pidan, seguro que te decreten; lejos de tomar fiado ni de ser admitido por fiador, que no es pequeña gloria; sin causa para ser ejecutado, sin trato para ejecutar; quitado de pleitos, contiendas y debates; últimamente, satisfecho que nada te oprima ni te quite el sueño haciéndote madrugar, pensando en lo que has de remediar. No todos lo pueden todo ni se olvidó Dios del pobre: camino le abrió con que viviese contento, no dándole más frío que como tuviese la ropa, y puede como el rico pasar si se quisiere reglar.

Mas esta vida no es para todos, y sin duda el primer inventor debió ser famosísimo filósofo, porque tan felice sosiego es de creer que tuvo principio de algún singular ingenio. Y, hablando verdad, lo que no es esto cuesta mucho trabajo y los que así no pasan son los que lo padecen y pagan, caminando con sobresaltos, contiendas y molestias, lisonjeando, idolatrando, ajustando por fuerza, encajando de maña, trayendo de los cabellos lo que ni se sufre ni llega ni se compadece; y cerrando los ojos a lo que importa ver, los tienen de lince para que el útil no se pase, siendo cosas que les importara más estar de todo punto ciegos, pues andan armando lazos, haciendo embelecos, desvelándose en cómo pasar adelante, poniendo trampas en que los otros caigan, por que se queden atrás. ¡Vanidad de vanidades y todo vanidad! ¡Qué triste cosa es de sufrir tanto número de calamidades, todas asestadas [...] para que la frágil y desventurada honra no se caiga, y el que la tiene más firme es el que vive con mayor sobresalto de reparos! ${ }^{15}$

Lo que vieron algunos escritores de los siglos XVI y XVII fue clave para la literatura española: la mirada del pobre era libre, al menos era más libre que la del poderoso, contradictoriamente. Y da igual que el pobre sea un vagabundo, un pícaro, como Lázaro de Tormes o Guzmán de Alfarache, que un hidalgo, como don Quijote. Lo que interesa es su libertad. Escuchemos ahora a Juan Carlos Rodríguez:

La literatura del pobre es quizá el verdadero nacimiento de la literatura [...] porque en ella el efecto «ficción real» del sujeto libre/autónomo funciona a velas desplegadas. Y sosteniéndose por sí sola (no por el prestigio del género o por el precio de la entrada) en la propia textualidad literal, a partir exclusivamente de tres pilares cimentadores que no sólo tratan de mostrarse o materializarse como ficción, sino que necesitan «demostrarse» verdaderos, legítimos. Y se trata precisamente de los tres pilares más básicos, y por ello también más débiles de la nueva problemática ideológica:

a) La cuestión de la vida propia. Los nobles o los santos no tienen vida.

b) La cuestión del nombre propio, esto es, la cuestión de la propia identidad. Los nobles tienen linaje y los frailes -o las monjas- al entrar en el convento se cambian de nombre. Los curas no conventuales siguen siendo siervos del Señor.

\footnotetext{
${ }^{14}$ Ibid., 344.

${ }^{15}$ Ed. de J. M. Micó (1992), 293-295.
} 
c) La cuestión del autor/sujeto propietario. Los nobles, o no saben escribir, o escriben poesía; pero no la publican; los curas que escriben del pobre, o son reformistas o escriben desde otro punto de vista. $^{16}$

Al margen de los términos, y de que Gamoneda separa rotundamente poesía de literatura, me interesa destacar de nuevo la libertad del pobre, de su mirada libre en todos los tiempos.

Sin embargo, y desde mi lectura de Cervantes, tengo la obligación de hacerme una pregunta: ¿Es la de Antonio Gamoneda, asimismo, una poética de la libertad? Sin duda, aunque, a juzgar por lo que él mismo dice, me parezca en ocasiones más barroca, en sentido puro, más gongorina incluso que cervantina. De hecho, dice la excelente entrevista con López de Abiada:

-Volvamos a la impossibilia y a la polisemia, a las múltiples significaciones, a las varias y variadas lecturas -todas válidas- que permite Descripción de la mentira.

-Me gusta que sea así. Me parece que no es malo que ocurra eso.[...]

-Pero posiblemente hay lectores de buena voluntad que te han hablado de la difícil digestión del libro: ¿No te han obligado sus observaciones a barajar la eventualidad de hacer una poesía más abordable?

-Yo creo que la continuación de mi poesía es (y se ve en Lápidas) más abordable. Lo que no sé es hasta qué punto ha podido pesar que me hayan dicho de Descripción de la mentira: «Es un libro muy duro, es difícil de entrar». Yo no tengo conciencia de partir de ese deseo del lector de buena voluntad. He ido a una literalidad más en primer término, más llana. No sé. Quizá por el peso de la edad. Bueno, yo he tenido la sensación de que Descripción de la mentira era un libro barroco, en cierto sentido. Pero yo no he reaccionado contra el libro, sino que el tiempo pasa y modifica el lenguaje poético. [...] La falta de localización temporal, espacial e histórica..., creo que puede pertenecer a una oscura voluntad, a una doble operación: no se trata únicamente de quitarle pistas y datos al lector, sino que al no dárselos, yo estoy favoreciendo la polisemia esa a la que tú te refieres, estoy posibilitando más lecturas; algo que me parece un artificio literario legítimo.

La polisemia, la multiplicidad es clave barroca, presente tanto en Cervantes como en Góngora y los demás, aunque el procedimiento gongorino más destacado sea muy diferente al de Gamoneda, pues se trata de acentuar referencias dispares, de multiplicarlas, en círculos concéntricos que rodean el objeto de múltiples sentidos, todos ellos a la par. Referencias y sentidos que son, además, con mucha frecuencia en Góngora, culturalistas, pues remiten a la historia antigua, a la emblemática, a la mitología grecolatina, etc. Se trata de un recurso que acercaría al poeta cordobés a los novísimos y al culturalismo de muchos poetas actuales, en la misma medida en que lo separaría de Gamoneda, que, como él dice, se limita a quitar referentes, a eliminar anclajes realistas o biográficos, para dejar el poema mucho más desnudo, mucho más abierto a la experiencia de cada lector, a su propia mirada, a su biografía, a su punto de vista, a su perspectiva personal. Y esto sí que es cervantismo puro, cervantismo en su más alto grado, pues de algún modo puede decirse que fue Cervantes el descubridor de que la clave no está en el texto, sino en el lector, no tanto en las palabras escritas cuanto en la mirada del que lee, y eso depende, entre otras cosas, de que no haya referencias realistas demasiado concretas, para que a la libertad del creador corresponda así la libertad del lector. Fue Cervantes, en suma, el descubridor del lector en toda su potencialidad. Gamoneda, sin duda, sigue su senda, si no sus pasos concretos.

Pero volviendo a Góngora: Gamoneda reconoce la dificultad de entrar en su poesía, y en eso, curiosamente, está mucho más cerca de Góngora que de Cervantes. No voy a insistir en esto, pero ya

${ }^{16}$ J. C. Rodríguez (1994), La literatura del pobre, 26. 
he comparado a los dos genios del XVII, y he llegado a la conclusión de que sus poéticas son muy parecidas, casi iguales, ligadas ambas al conceptismo medular en el barroco, pero con una diferencia fundamental: lo difícil en Góngora es entrar, pero una vez dentro, sabidas sus claves, todo discurre con facilidad y salir es muy fácil, mientras que en Cervantes sucede al revés, pues la entrada es tan fácil como dificultosa la salida ${ }^{17}$. Aunque en el último Gamoneda tan difícil es la entrada como la salida, en asunción de ambas poéticas barrocas, cervantina y gongorina, a la par.

Cervantes, como he estudiado en Poética de la libertad, sostiene una libertad estética que, resumiéndola en cuatro palabras: 1) aboga por la libertad en general, 2) libera a los personajes de sus corsés retóricos convencionales: don Quijote nace sin ataduras que lo lastren, nace ya viejo, sin que sepamos nada de su «lugar», de su tiempo, de sus padres, ni de su vida anterior. 3) Incluso hace que las biografías de sus héroes contradigan expresamente el determinismo de la herencia biológica y del medio ambiente, como sucede en los casos de Preciosa (Gitanilla) y Constanza (Fregona). 4) Y, sobre todo, como Gamoneda [recuérdense sus palabras: «la falta de localización temporal, espacial e histórica, creo que puede pertenecer a una oscura voluntad, a una doble operación: no se trata únicamente de quitarle pistas y datos al lector, sino que al no dárselos, yo estoy favoreciendo la polisemia esa a la que tú te refieres, estoy posibilitando más lecturas; algo que me parece un artificio literario legítimo»], da libertad al lector, a quien remite, incluso expresamente, la interpretación de sus ambiguas creaciones, como hace en el episodio de «la cueva de Montesinos», donde don Quijote dice haber estado tres días, mientras Sancho afirma que no pasó de una hora, y una nota marginal apela al lector: «tú, lector, pues eres prudente, juzga lo que te pareciere»; o le hace responsable incluso de la ejemplaridad de sus novelas cortas: «si bien lo miras...». 5) Y todo ello para darse a sí mismo la libertad que necesita todo escritor y distanciarse de su creación lo suficiente como para no encariñarse en exceso ni identificarse demasiado con sus héroes, mediante filtros interpuestos, otros narradores, la ironía, etc.

En un sentido estricto, por tanto, la poética de la pobreza, común a los dos escritores, es también una poética de la libertad. Así lo dice Gamoneda de Cervantes:

El lenguaje representativo de este ser y de este acontecer en poesía, yo lo advierto ligado a la cultura de la pobreza. La relación dialéctica entre el poder injusto y el sufrimiento está prácticamente en todas las «locas aventuras» que configuran el curso poético del Quijote. Es hondamente significativo que Cervantes, al cerrar este curso, nos ofrezca la pérdida de la locura como preámbulo de la muerte.

Y así es, en verdad. Pero no solo en el Quijote, sino en todas sus obras. Recuérdense, por ejemplo, las Novela ejemplares, donde el perro que acata las normas sociales, el más honesto, el que sigue la moral católica, Berganza, acaba marginado de la sociedad llevando las linternas de Mahudes extramuros de Valladolid, en el Coloquio de los perros, mientras triunfan en Sevilla todos los

\footnotetext{
${ }^{17}$ Reproduzco mis propias palabras: «Aunque, para concluir, me gustaría reiterar de nuevo que también la dificultad es común a los dos maestros de nuestras letras áureas, dado que tan arduo es entrar en la obra de Góngora como salir de la de Cervantes, pues tan oscura es la una como la otra, ya que, una vez superado el acceso al laberinto gongorino, todo es fácil, justo a la inversa de lo que acontece en el laberinto de Cervantes, de acceso abierto a todos, aunque de muy difícil salida airosa». A. Rey Hazas (2005), Poética de la libertad y otras claves cervantinas, 173.
} 
delincuentes y los que incumplen las normas sociales y morales, como los jiferos ladrones del matadero, los pastores que roban sus propias ovejas, los alguaciles corruptos que se unen a los ladrones, etc. De igual manera, Cervantes rompe una lanza por las mujeres más desfavorecidas y convierte a una gitana y a una moza de mesón, que eran dos prostitutas según la mentalidad de la época, en dos modelos de mujeres honestas, sin tacha, ejemplares incluso para el matrimonio cristiano de la época, en $L a$ gitanilla y La ilustre fregona. O denuncia el funcionamiento de una sociedad en la que el mejor estudiante de la Universidad de Salamanca, tras una locura en la que se cree de vidrio, recupera la cordura, pero la sociedad no le acepta, no encuentra en ella un lugar, y se ve obligado a convertirse en soldado, para morir heroicamente en Flandes. Todos y todas son pobres, marginados, víctimas: todos son defendidos por Cervantes, que hace de ellos y de ellas ejemplos insignes de los valores de ese mundo. Tal es su poética de la pobreza: una poética de la libertad individual, sin duda, pero asimismo una poética de la contradicción sociomoral que esa libertad individual implicaba e implica, y, claro está, una defensa literaria permanente de los más humildes, de los más necesitados.

Por eso, entre otras razones, no se le ha pasado a Gamoneda que Cervantes es un inmenso poeta en el Quijote, y no solo porque «es el origen de la novela moderna», sino también porque

\begin{abstract}
instaló bien instalada la poesía moderna en el seno de la narratividad. [...] Me interesa precisar aquí que el pensamiento específicamente poético se distingue del pensamiento discursivo, reflexivo o de cualquiera otra especie, en que procede de lo desconocido -de lo desconocido incluso por el propio poeta- y en que lo revela; en que realiza lo irreal; en que puede crear lo que no existía; y en que se hace presente precisamente en un instante en que se produce la disolución de la normativa común del pensar. Una vez más, aquí, el «no saber sabiendo» de Juan de Yepes. Yo, en mi pequeñez, he argumentado en alguna ocasión «que no sé lo que sé hasta que no me lo dicen mis propias y ya escritas palabras».A Cervantes, en su grandeza, creo que le ocurría algo parecido.
\end{abstract}

Por mi parte, y sin entrar en los valores poéticos del Quijote, que han defendido también poetas de relieve como Luis Cernuda, León Felipe, Caballero Bonal y tantos otros, no sé si, como piensa Gamoneda, don Quijote y Sancho son «un discurso inconscientemente activado, una emanación impensada de su vida». A mí Cervantes me parece bastante más racional y reflexivo, y, en ese sentido, menos poético. Sí tiene, en ocasiones, ese «no saber sabiendo», pero solo en momentos contados. La mayor parte está controlada, aunque el control se haya producido sobre la marcha, sin un plan previo, pero finalmente, tras haber cometido muchos errores y tras varias vacilaciones y omisiones, todo queda controlado por una poética de la pobreza y de la libertad mucho más consciente, a mi entender, de lo que piensa Gamoneda. Porque la polisemia, la riqueza de significados, depende de la ambigüedad del texto, aumentada por la experiencia personal, la ideología o las creencias de cada lector, sometido a los espejos y máscaras de autores varios, archivos supuestos, y personajes diferentes; esto es, a una ambigüedad creada por Cervantes sistemática y conscientemente. El efecto final puede ser el de un «discurso [que parezca] inconscientemente activado»; pero no lo es: en verdad, a lo que creo, es el resultado de una poética consciente y voluntaria, que produce en el lector esos efectos de activación inconsciente de que habla nuestro poeta. 
De hecho, también Gamoneda lo hace, y lo dice, qué duda cabe; pero asimismo hace y dice lo contrario. Es verdad que, como él mismo afirma, se mueve en la contradicción, tal y como responde una vez a Marcos Taracido:

[...] yo digo lo que digo, lo que digo y otras cosas; eso es lo que ocurre con la poesía, que dices lo que dices más algo que se desconoce, entonces cuando la contemplación de la muerte se hace desde el amor a la vida, cuando -y está muy bien dicho y muy bien pensado eso que dijiste antes- entras en la aparente frivolidad de esa negatividad y esa desolación intentar convertirlas en una obra de arte con el lenguaje cambia el sentido, cambia la naturaleza; dices, pero también estás haciendo otra cosa que de alguna manera se entiende que proporciona placer, quizás porque estás haciendo una afirmación de la vida casi un poco carnal, si aceptamos que el lenguaje pueda ser un cuerpo. Y se da esa doble significación que es contradictoria, pero es que esa contradicción yo entiendo que está muy bien. La contradicción es una forma de energía, puede generar una energía.

Es verdad que Cervantes podría asumir en buena medida muchos versos magníficos de Gamoneda, pese a la diferencia inmensa de tiempo, espacio, historia y cultura que los separa, y decir con él, por ejemplo, «amé todas las pérdidas», «amé las desapariciones». Quizá no diría: «así fue nuestra edad: atravesábamos las creencias». Porque, a la hora de morir demostró que mantenía su fe católica. Sí podría decir, no obstante: «así fue nuestra edad: pero yo atravesaba las creencias»; o algo similar, porque tan rebelde fue Cervantes en el quinientos como lo es ahora Gamoneda. Es verdad que Cervantes se mueve asimismo entre contradicciones de toda índole, que analiza o denuncia, como hemos visto; aunque sin llegar a los extremos de nuestro poeta, cuando dice que «la contradicción está en mi alma como los dientes en la boca que habla de misericordia».

Se ha dicho a menudo que los títulos cervantinos son contradictorios, que, por ejemplo, no se aviene bien «ingenioso» con «hidalgo», términos quijotescos que se repelen, pues no era precisamente el ingenio lo que caracterizaba a los escuderos, más bien romos; por no hablar de los sentidos opuestos y enfrentados de «quijote», ni de a qué «mancha» se refiere Cervantes en su novela inmortal, si a la geográfica o a la de sangre, etc. De la misma manera, «novelas» y «ejemplares» son palabras que encajan muy mal, dada la mala fama que tenía la herencia de Boccaccio, contraria a cualquier lección moral, enemiga de toda ejemplaridad. Los títulos de los poemarios del leonés son también contradictorios, en buena coherencia con el contenido y la forma de sus poemas, y corroboran o desvelan, o ambas cosas a la vez, la contradicción que está en el centro de la poesía de Gamoneda: Sublevación inmóvil (1953-1959 y 2003) no puede ser más claro, porque la sublevación implica acción, obviamente, nunca inmovilidad. Lo mismo le sucede a Exentos I (1959-1960 y 2003) у Exentos II (1963-1970 y 2003), es decir «libres»; ya que son poemas que ostentan su libertad en una España sin ella; versos que presumen de su exención, cuando están, al contrario, plenamente comprometidos con la realidad. En medio, Blues castellano (1961-1966 y 2004) insiste en el choque de opuestos, pues nada más lejos de la dulzaina y el tamboril de la vieja Castilla que la música negra del blues norteamericano. Descripción de la mentira (1975-1976 y 2003) es otro título igual de chocante, o más, porque la mentira no se puede describir, de un lado, y porque el libro no describe sino que desvela el disfraz de verdad de la España de la mentira. Lápidas (1977-1986 y 2003) no es un libro de epitafios ni se refiere a las tumbas de los muertos, sino que poetiza la vida y sus sinsentidos. El libro del frío 
(1996-1998, 1998 y 2004), de la misma manera, no es un tratado meteorológico ni un manual de instrucciones para congelar alimentos o un folleto de funcionamiento de frigoríficos, ni nada que se le asemeje, pese a su título, sino una reflexión lírica sobre la vejez y la muerte próxima. Arden las pérdidas (1993-2003 y 2004) implica otro imposible semejante a Descripción de la mentira, porque ni se queman las abstracciones ni se describen las mentiras, sino los objetos. Cecilia (200-2004), en fin, es el único que no implica ninguna contradicción, aunque el propio Gamoneda y su mujer tuvieron la amabilidad de decirme, tras mi intervención en el congreso, que tenía razón en mi lectura, porque también el primer título de Cecilia -que ahora no recuerdo ${ }^{18}$, había sido completamente contradictorio, como todos los demás, aunque finalmente el poeta decidió cambiarlo por el de Cecilia $^{19}$.

Y, sobre todo, es verdad que biografía y literatura, vida y poesía son indisociables para ambos. Cervantes no pudo ni quiso separarse nunca de sus experiencias en Italia, Lepanto, Argel, La Mancha o Andalucía ${ }^{20}$. Gamoneda tampoco, como dice en El cuerpo de los símbolos ${ }^{21}$, «la poesía [...] crea realidad $[\ldots]$ y engendra conocimiento», pero no sustituye a la vida, sino que la «intensifica», porque es, dice, «el relato de cómo voy a la muerte», y por tanto, la poesía es tiempo, memoria, «pero la memoria es siempre conciencia [...] de consunción del tiempo correspondiente a mi vida, y, por esto mismo, conciencia de ir hacia la muerte ${ }^{22}$. Y en su caso concreto, para ser exactos, la memoria y el pensamiento «son posteriores a un impulso musical», por eso, afirma: «sólo sé lo que digo cuando ya está dicho» ${ }^{23}$. En consecuencia, «lo que Gamoneda deja escrito procede directamente de su sangre y de sus humores». «La lucidez de Gamoneda - prosigue Clara Janés ${ }^{24}$ - se desarrolla en ese clima del que va por los caminos, un clima de reflexión. Es su andadura, el poeta atraviesa espacios y tiempos. Y esos espacios y tiempos exteriores cruzan a su vez el límite hacia el interior, catalizador de la memoria. [...] Como consecuencia, en esta construcción el olvido desempeña un papel importante».

Sobre la contradicción del mundo y de la realidad, ya hemos hablado, aparte de que no es necesario insistir, dada su obviedad. Me interesa más, por ello, la contradicción interna del poeta. ¿A qué se debe? ¿Podemos explicarla? El poeta nos ayuda a ver alguna luz. Leamos sus declaraciones y sus versos.

Gamoneda habla en ocasiones de su lucha interior. Por ejemplo, en su discurso del premio Cervantes sobre la «cultura de la pobreza». Oigámosle:

\footnotetext{
${ }^{18}$ Desgraciadamente no lo apunté, pero Antonio Gamoneda y su esposa pueden corroborarlo.

${ }^{19}$ Estas palabras proceden de mi artículo «La poesía de Antonio Gamoneda: reflexiones sobre su sintaxis de la quiebra, su estética de la verdad y su falta de ironía», que se publicó en el volumen de Leer y entender la poesía, Homenaje a Antonio Gamoneda, 2010.

${ }^{20}$ Véase, simplemente, mi libro Miguel de Cervantes. Literatura y vida, ed. ampliada y renovada, 2005. Una síntesis más ajustada y nueva, si se quiere, en las voces Literatura y vida, y Libertad, que he redactado para la Enciclopedia Cervantina, 2010, vol. VII.

${ }^{21}$ A. Gamoneda (1997), El cuerpo de los símbolos, 35.

22 Ibid., 24.

23 Ibid., 26.

${ }^{24}$ C. Janés (2007), «Antonio Gamoneda: de vértigo y olvido», Revista de Occidente, 66.
} 
El poeta es un ser impúdico. Si yo tuviera verdadero respeto a todas esas cosas, tendría que practicar el silencio, que es lo que he practicado durante mucho tiempo. En ese sentido, la escritura es una forma de indignidad. Lo que pasa es que la asumo también, entro en el juego trivial y terrible de convertir lo más serio de mi existencia y de la de los que están a mi lado en un objeto para el placer, porque el poema, con independencia de lo que diga, incluso el poema que habla del sufrimiento más atroz, es un objeto para el placer; y añado: la memoria del sufrimiento o el sufrimiento mismo generan la necesidad de consolación. $\mathrm{Y}$ esa consolación está en el placer que produce la materialización, la conversión de eso en un objeto de otra especie, en un objeto con otra función añadida que lo hace más tolerable. Para mí la poesía es, en última instancia, consolación.

Son palabras casi mágicas, desentrañadoras, de una sinceridad y de una hondura pasmosas. Ya lo había dicho antes, en verso o prosa poética. Recordemos algún ejemplo notorio:

Sé que el único canto,

el único digno de los cantos antiguos,

la única poesía

es la que calla y aún ama este mundo, esta soledad que enloquece y despoja. (Exentos I)

Con su lucidez habitual, su palabra exacta, precisa, y su rabiosa sinceridad, Antonio Gamoneda nos da las claves de su creación: lo único digno es el silencio, «la única poesía / es la que calla». Pero el poeta es un creador, siente sobre todo el placer de la creación, de la escritura, por encima de cualquier otra consideración: «incluso el poema que habla del sufrimiento más atroz, es un objeto para el placer». Se trata, en consecuencia, de un placer estético, del placer que produce la transfiguración literaria, o mejor, poética, de cualquier asunto, la que convierte cualquier cosa «en un objeto de otra especie», en un poema. Esa es la razón por la que «la poesía es, en última instancia, consolación», al decir del poeta leonés, dado que, la belleza poética conforta al creador, consuela el dolor de sus contenidos.

No se olvide que, en última instancia, que algo aparezca como vida o como literatura a ojos del lector depende del propio artificio literario o poético: en El curioso impertinente quijotesco, por ejemplo, los personajes de una novela, que figura así, como tal novela, dentro del texto, esto es, Lotario y Anselmo son capaces no solo de escribir y leer sonetos de amor, sino de mantener una conversación teórica sobre si los poetas enamorados dicen o no la verdad:

-Luego, ¿todo aquello que los poetas enamorados dicen es verdad?

-En cuanto poetas no la dicen -respondió Lotario-; mas, en cuanto enamorados, siempre quedan tan cortos como verdaderos.

-No hay duda deso -replicó Anselmo. (I, 24).

En consecuencia, estos personajes, frente a los sonetos, que son literatura, parecen de carne y hueso, dado que los escriben, leen y comentan incluso si dicen o no la verdad; pero como personajes de ficción, de una novela llamada El curioso impertinente, acaecida en Florencia, que lee el cura en una venta manchega, son literatura, nada más que literatura, y, por tanto, hacen parecer seres de verdad al cura, al barbero, a don Quijote, Sancho, etc., dado que leen y juzgan este relato. Pero, a su vez, don Quijote y los demás son entes de ficción, claro está, de una obra escrita en árabe por un tal Cide Hamete, lo que da vida a este autor arábigo meramente ficticio, pues no es otra cosa que una invención del autodenominado «segundo autor», que hace traducir el manuscrito a un morisco aljamiado del 
Alcaná de Toledo... Todos, unos y otros, meros entes de ficción, aunque parezcan a veces más reales que la realidad; todos, en fin, obra de Cervantes, o mejor, de su pluma: «para mí sola nació don Quijote». Y es que todo, absolutamente todo, hasta que unas palabras parezcan, o no, vida auténtica, depende del texto, de la literatura, de procedimientos estéticos. Y Gamoneda lo sabe bien. Cervantes, por ende, estaría plenamente de acuerdo con nuestro poeta en la consolación que da la belleza, en el placer de la escritura, más allá del dolor intenso auténtico que nace de la dolorosa realidad en que se inspira.

Con todo, Gamoneda es mucho más pesimista que Cervantes, más próximo a Quevedo, en ese sentido, si se quiere hacer una comparación con un contemporáneo del autor del Quijote. Cervantes siempre deja abierta la puerta a la esperanza, justo al contrario que nuestro poeta, para quien «Ahora ya no queda tabaco ni esperanza», «otros os engañáis con la esperanza», «no tengo miedo ni esperanza», o hay «placer sin esperanza», etc. Y es más pesimista, con independencia de que deje o no una sensación de pesimismo en el lector. Pues con frecuencia no la deja, ya que predomina la estética. De hecho, la pregunta de Marcos Taracido a la respuesta que he anticipado, implica toda una interpretación en este sentido, pues reza así: «toda la obra tuya es absolutamente pesimista; sin embargo es maravillosamente optimista por la belleza del lenguaje, es decir, la manera en que está contado crea optimismo». Y así es.

Gamoneda es muy consciente de sus recursos, que son, como en el siguiente caso, muy semejantes a los de don Miguel. Le dice a López Abiada:

Yo tengo casi la misma actitud para dialogar con el «tú» desconocido, con el «tú» que tiene nombre en mi conciencia y que no soy yo, y con el «tú» que sé que soy yo. En mi discurso yo no tengo dificultades para dialogar conmigo. No hago del «yo» un personaje recurriendo al mecanismo de llamarle «tú». Al menos, no tengo conciencia de ello.

Recursos que son coincidentes con los de Cervantes, y están en la base, a mi entender consciente, de la «emanación inconsciente» de que habla nuestro poeta, por más que el reconocimiento de su capacidad lectora me haga dudar. En cualquier caso, puede aceptarse la contradicción, si consideramos que el Quijote es principalmente poesía, y que, por consiguiente, «en el lenguaje poético, [...] los molinos son gigantes, los gigantes son poderosos, su ejercicio es la maldad, y el Caballero de la Eterna Juventud, el abatido, nos revela que su infortunada verdad consiste en la causa necesaria de luchar contra esa maldad».

Hay, en fin, una coincidencia de carácter entre Gamoneda y el autor del Quijote que es de extraordinario interés para explicar sus numerosas semejanzas: la melancolía de ambos, la melancolía que Cervantes encarna en don Quijote y Gamoneda en toda su poesía, y era el temperamento, el «humor» de los poetas, los creadores y los inteligentes de los siglos XVI y XVII. «El temperamento acedíoso y retraído del poeta Gamoneda encuentra su cauce terapéutico - dice Rodríguez de la Flor ${ }^{25}$ en la efusión de una tinta de la melancolía que presta a sus páginas de siempre una tonalidad única, singularizándolas con la marca ambigua que tradicionalmente han recibido los productos generados

${ }^{25}$ Y Amelia Gamoneda (2006), A. Gamoneda, Sílabas negras, 54. 
por los hijos y la prole de Sarturno». En efecto, ambigüedad, indagación artística en los límites vedados para otros, desencanto, pasión creadora, placer del texto, profundidad, capacidad de sobreponerse a la propia realidad adversa, etc. son rasgos de la melancolía que establece puentes obvios entre Cervantes y Gamoneda.

Pero hay también muchas diferencias, como es natural, entre el quehacer cervantino y el del poeta leonés, dentro de una poética en parte común y de un temperamento en cierta medida semejante, que se deben a su carácter distinto, a su personalidad diferente, y no sólo a sus épocas y tiempos, tan distantes. No me refiero, por tanto, ahora, a razones históricas, no tengo en cuenta que Cervantes fuera un héroe de España o de Castilla y de su religión católica, ni a que luego se desengañara del heroísmo y «atravesara» incluso «las creencias» de su época; porque, finalmente, tanto su héroe más destacado como él mismo se atuvieron a las pautas ortodoxas de bien morir, a los ars moriendi católicos entonces vigentes.

Pero, insisto, no me refiero a esas desemejanzas, obvias y naturales, sino a cuestiones de talante personal, que son el algún caso muy diferentes. Y sobre todo, me refiero a una en particular; la ironía, clave medular de la literatura cervantina, eje que le permite el distanciamiento de creador genial, y hace posible el perspectivismo de sus personajes, el que caracteriza su mundo, e incluso explica, lejanamente, el origen de la filosofía de Ortega, a quien cita, dicho sea de paso, a menudo Gamoneda, pues nace en un libro llamado Meditaciones del Quijote, que sistematiza lo ya hecho y dicho por la obra cervantina. La ironía axial de Cervantes, que es talante y recurso, procedimiento y clave literaria, que es todo a la vez, vida y literatura, falta por completo, o casi, en la obra poética de Gamoneda. Lo dicen muy bien Amelia Gamoneda y Fernando Rodríguez de la Flor. A sus palabras me atengo:

Una privación, la falta misma de un mecanismo decisivo en los procesos del arte de la posmodernidad, como es la ironía (con un reverso que debemos leer así: donde no hay ironía, es que hay dolor), le opone taxativamente también a quien hace de la misma el motor de su propia representación. [...] Incapaz de ironizar sobre sí mismo, y menos sobre la clase perdedora en que ha crecido su experiencia, el poeta ha sabido ver en este mecanismo lo que tiene de vergonzante confesión de un privilegio. [...] «Yo no he metido en un mismo cesto ironía y sufrimiento», declara de un modo casi acusador, y, al hacerlo, cuidadosamente elige el sufrimiento para trazar este opuesto polo de la ironía. El sufrimiento sentido (que es sentimiento en conjunto, dolor coral, común) se opone así a las elecciones de exclusivo signo estético que alientan o fundamentan el régimen actual de la sobras de arte verbal. Definitivamente curado de y puesto a salvo del otro lado de la ironía, en virtud de una asunción del «dolor del mundo», a Gamoneda sólo le queda en este plano de lo colectivo la solidaridad. ${ }^{26}$

Quizá por eso le parezca «inconsciente» a nuestra gran poeta la capacidad poética cervantina, pues no sería disparatado pensar que, lejos de la ironía cervantina, quizá por mero temperamento personal, se le escaparan algunos de sus mecanismos literarios. ¡Quién sabe! Sea como fuere, es probablemente una cuestión de carácter individual.

Pero eso no afecta a mi argumentación, en la que se demuestra, si no ando errado, que, elecciones personales aparte, la poética de la pobreza deviene finalmente en poética de la libertad, más allá de que la pobreza condicione quizá más al poeta leonés que al inaugurador de la novela moderna. Me

${ }^{26}$ Ibid., 49-51. 
interesa en todo caso destacar que las lúcidas palabras de nuestro impar poeta leonés sobre Cervantes y la pobreza ayudan mucho a la comprensión cabal del creador de la novela, pero no menos -y es lo que me ocupa- que a entrar en los oscuros y hondos poemas, en los «paraísos cerrados para muchos», parafraseando a Soto de Rojas, del propio Gamoneda.

No hay que olvidar, sin embargo, que para el asturleonés, hombre de su tiempo al fin, no existe la eternidad, no hay Dios ni esperanza ultraterrena: «la imposibilidad es nuestra iglesia» - dice- «No hay nada más allá de la última profecía. Hemos soñado que un dios lamía nuestras manos: nadie verá su máscara divina». En ese contexto, un poema acaba afirmando que:

Así las cosas, la locura es perfecta.

La locura, qué curioso, una de las claves de la obra cervantina como se sabe: eje de Don Quijote y del Licenciado Vidriera. Recordemos, simplemente, unas hermosas y atinadas palabras de Tiempo de silencio (1962), de Luis Martín Santos, sobre el particular:

Cervantes, Cervantes. ¿Puede realmente haber existido en semejante pueblo, en tal ciudad [Madrid] como ésta, en tales calles insignificantes y vulgares un hombre que tuviera esa visión de lo humano, esa creencia en la libertad, esa melancolía desengañada tan lejana de todo heroísmo como de toda exageración, de todo fanatismo como de toda certeza? [...] ¿Qué es lo que ha querido decirnos el hombre que más sabía del hombre de su tiempo? ¿Qué significa que quien sabía que la locura no es sino la nada, el hueco, lo vacío, afirmara que solamente en la locura reposa el ser-moral del hombre? ${ }^{27}$

Cervantes era un católico, seguramente inconformista y crítico, pero un creyente, al fin y al cabo, siempre esperanzado, hasta en la muerte, como buen español barroco, que acaba por adoptar el hábito de la orden Tercera de San Francisco para bien morir. Gamoneda no es así, pues cree que no hay nada y que por eso la locura es perfecta. En eso coincide con Cervantes, sin duda, una vez más, pese a las diferencias enormes de credo y fe, y sobre todo de esperanza, pues para Gamoneda lo único real es la desaparición: «somos reales en la desaparición».

También, harto significativamente, coincide la Edad de Hierro contra la que lucha don Quijote para reinstaurar la Edad de Oro. En el poeta leonés solo queda, claro está, la de Hierro, como en Cervantes, aunque para se trata de la vejez, de la misma vejez del Cervantes franciscano, siglos más tarde, en la que escribe: «ésta es la edad del hierro en la garganta», el tiempo último en que de su boca solo «caen sílabas negras», «y sabes que es lo real lo que no existe», dice, como sucede en los mundos imaginarios de don Quijote: ¡qué curioso!, ¡qué significativo!. Y acaba:

\footnotetext{
Así es la edad del hierro en la garganta. Ya todo es incomprensible. Sin embargo, amas aún cuanto has perdido.
}

La misma inquietud poética y literaria, que lleva a los dos escritores a la búsqueda de la verdad, concluye al final con el fracaso de esa búsqueda. A la postre, dice Gamoneda, «la verdad es un armario lleno de sombra». Para él no hay regreso, porque lo único que espera es la nada, la muerte. Todo muere,

${ }^{27}$ L. Martín Santos (1962), Tiempo de silencio, 61-62. 
todo acaba: «Así las cosas, ¿de qué perdida claridad venimos? ¿Quién puede recordar la inexistencia? Podría ser más dulce regresar, pero entramos indecisos en un bosque de espinos». Queda, eso sí, igual que en Cervantes, el placer de crear, el placer estético, de la belleza, aunque sea sin esperanza; de los espinos, que simbolizan la hermosura de su tierra y de su lírica. Pero no deja de ser placer, un placer que permanece, que se resiste a la muerte, que perdura tras ella: la obra poética. «Hay una música en mí, esto es cierto, y todavía me pregunto qué significa este placer sin esperanza».

Gamoneda constata, con una belleza poética llena de imágenes inéditas, de metáforas nuevas, con un lenguaje lirico originalísimo, pero constata, en fin, el dolor intenso, las lágrimas negras, la injusticia, la crueldad, la angustia... de la humanidad doliente. Sin dudas ni paliativos. Pero en un momento dado de su evolución alcanza a advertir «la imposibilidad de distinguir la crueldad de la misericordia» ${ }^{28}$. Así, en el escalofriante poema autobiográfico de Arden las pérdidas, que empieza: «Vi descender llamas doradas», pese a las «huellas judiciales» $\mathrm{y}$ «los huesos torturados» que vio (siempre dice «vi»), también llegó a ver («advertí», dice), «la belleza de ciertas úlceras y, en el tejido arterial, las tuberías que comunican el placer y la muerte» ${ }^{29}$; soñó luego «otra vida dentro de su [mi] cuerpo». El sueño y la vida, tan cervantinos, tan barrocos.

El placer de crear es indudable, al lado del también incuestionable dolor por la humanidad. Para Gamoneda, como para Cervantes, no se pueden separar vida y obra, los pinchazos de la una y el placer de crear la otra: ambas van a la par, caminan juntas, son inseparables. Por eso, el poema acaba así:

Ésta es mi relación, ésta es mi obra. No hay nada más en la alcoba fría. Fuera de ella, abandonadas, están las cestas de la tristeza, excrementos cubiertos de rocío, y los grandes anuncios de la felicidad.

\section{Referencias bibliográficas}

Alemán, Mateo, Guzmán de Alfarache, ed. de J. M. Micó, Madrid, Cátedra, 1992.

Cartas de algunos padres de la Compañía de Jesús, tomo I, en Memorial Histórico Español, Madrid, Imprenta Nacional, 1861, tomo XIII.

CASADO, Miguel, «Introducción», Edad, Madrid, Cátedra, 1988.

Claube, Joseph M. (pseudónimo), «La poesía lírica de Cervantes», Homenaje a Cervantes, Cuadernos de Ínsula, I (1948), 151-187.

GAmonedA, Amelia, A. Gamoneda, Sílabas negras, Salamanca, Servicio de Publicaciones Universidad de Universidad, 2006.

GAmONEDA, Antonio, El cuerpo de los símbolos, Madrid, Huerga y Fierro, 1997.

, Esta luz. Poesía reunida (1947-2004), Barcelona, Galaxia Gutenberg-Círculo de Lectores, 2004.

Herrera Puga, Pedro, Sociedad y delincuencia en el Siglo de Oro, Madrid, BAC, 1974.

JANÉS, Clara, «Antonio Gamoneda: de vértigo y olvido», Revista de Occidente, 311 (abril de 2007).

\footnotetext{
${ }^{28}$ A. Gamoneda, Esta luz, op. cit., 468.

${ }^{29}$ Ibid., 469.
} 
LóPEZ DE AbIADA, José Manuel, 30 / VIII, 1990, AnMal electrónica (Analecta Malacitana), 15 de junio de 2004.

LunA, Juan de, Segunda parte del Lazarillo de Tormes, ed. Pedro Piñero, 1620, Madrid, Editora Nacional, 1977.

Martín SAntos, Luis, Tiempo de silencio, Barcelona, Seix Barral, 1962.

Rey HaZAs, Antonio, Cervantes. Obra Completa, 12, Madrid, Alianza Editorial, 1997.

—_, «Cervantes se reescribe: teatro y Novelas Ejemplares», Criticón, 76, 1999.

—., Poética de la libertad y otras claves cervantinas, Madrid, Eneida, 2005.

—, Miguel de Cervantes. Literatura y vida, ed. ampliada y renovada, Madrid, Alianza Editorial, 2005

— L Literatura y vida, y Libertad, Enciclopedia Cervantina, vol. VII, CEC, Alcalá de Henares, 2010.

— Leer y entender la poesía, Homenaje a Antonio Gamoneda, Universidad de Castilla-La Mancha, 2010.

RoDRíGUEZ, Juan Carlos, La literatura del pobre, Granda, Ed. de guante blanco, 1994. 